UDC 347.51

LBC 67.404.219

\title{
FROM CLAIM TO THE RIGHT IN TORT OBLIGATIONS
}

\author{
Lyudmila A. Chegovadze \\ Russian Presidential Academy of National Economy and Public Administration; \\ N.I. Lobachevsky State University of Nizhny Novgorod, Nizhny Novgorod, Russian Federation
}

\begin{abstract}
Introduction: the grounds for contractual obligations are the actions to conclude the agreement regulated by the law, as well as the enforcement actions of the parties of the formally non-concluded agreement which eliminate the state of legal uncertainty. The law does not regulate and prohibits the actions to cause harm, as a result of which there are tort obligations, therefore, in civil law, with the rare exceptions, they are considered as a measure of responsibility. However, the approach to the basis of the tort obligation as an offense is not based on the standard; the offense is determined by the scientists, and therefore, the question of the concept and criminal wrongdoing is acutely debatable.
\end{abstract}

Methods: the methodological framework for this study is a set of methods of scientific cognition, among which the main are the methods of consistency, analysis and comparative law. Results: justified in the work the author's point of view is based on the legislation and the competent academic community's opinions of the existence of the independent civil-law mechanism for the creation of obligations as a result of causing harm, based on the fact that the presence of a mediated connection of a tort obligation with an act of causing harm does not mean that this act directly generates it. On the basis of the legal analysis of the norms the Russian Federation Civil Code and the doctrine about the legal consequences the author conducts the investigation of the state of civil law relations upon the fact of injury. The issues of the legal regulation of absolute relations in case of need to protect the subjective right of one of the parties are raised.

Conclusions: it was found that as a legal consequence the indemnity obligation is established as a result of legitimate actions - independent protective actions of one individual in response to the violation of his right by another person. In order to substantiate a claim to protection, it is sufficient to prove that the act which caused the injury is not permitted (prohibited) by law or is committed beyond the pale and that it inevitably causes the harmful result whose elimination is asked by the victim. The subjective evaluation of act act has no legal significance, just as its illegal or lawful nature - the law prohibits harm not only by illegal actions, but also by lawful ones as well (Art. 16.1 of the Civil Code of the Russian Federation).

Key words: act of causing damage, legal consequences, claim to protection, state of civil legal relations, lawful legal acts, violation of absolute rights, mechanism of tort obligations, causal link.

УДК 347.51

ББК 67.404.219

\section{ОТ ПРИТЯЗАНИЯ ДО ПРАВА В ДЕЛИКТНЫХ ОБЯЗАТЕЛЬСТВАХ}

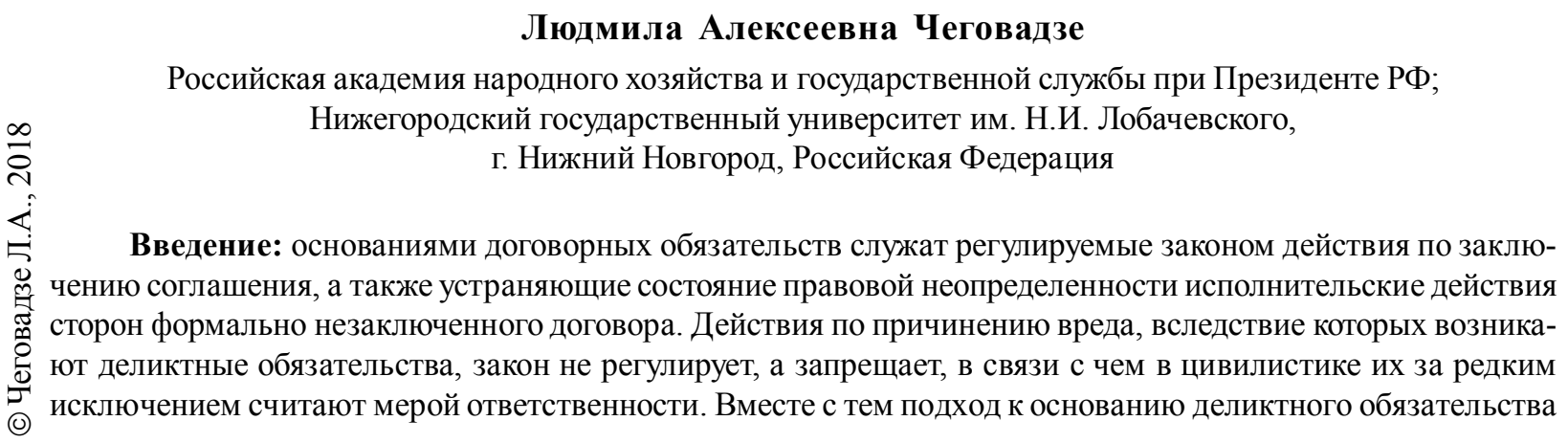


как к правонарушению не основан нормативно, состав правонарушения определяется учеными, в связи с чем вопрос о понятии и составе гражданского правонарушения является остро дискуссионным.

Методы: методологическую основу данного исследования составляет совокупность методов научного познания, среди которых основное место занимают методы системности, анализа и сравнительно-правовой. Результаты: обоснованная в работе авторская позиция опирается на законодательство и мнения компетентной научной среды о наличии самостоятельного гражданско-правового механизма возникновения обязательств вследствие причинения вреда, исходя из того, что наличие опосредованной связи деликтного обязательства с актом причинения вреда не означает, что непосредственно этот акт его и порождает. На основании правового анализа норм ГК РФ и учения о правовых последствиях проводится исследование состояния гражданско-правового отношения по факту причинения вреда. Поднимаются вопросы правовой регламентации абсолютных отношений в случае необходимости защиты субъективного права одной из сторон.

Выводы: выявлено, что в качестве правового последствия обязательство по возмещению вреда устанавливается как результат правомерных действий - инициативно-защитных действий одного лица в ответ на нарушение его права другим лицом. Для обоснования притязания на защиту достаточно доказать, что деяние, которым причинен вред, не дозволено (запрещено) законом либо совершено за пределами дозволенного и что оно с неизбежностью вызывает тот вредоносный результат, об устранении которого просит потерпевший. Субъективная оценка деяния не имеет правоустанавливающего значения, точно так же, как и его противоправный или правомерный характер - закон запрещает причинять вред не только незаконными действиями, но также и правомерными (ст. 16.1 ГК).

Ключевые слова: акт причинения вреда, правовые последствия, притязание на защиту, состояние гражданского правоотношения, правомерные дозволенные деяния, нарушение абсолютного права, механизм возникновения деликтного обязательства, причинно-следственная связь.

Общеизвестно деление обязательств на договорные и внедоговорные и выделение в числе последних деликтов или обязательств вследствие причинения вреда другому лицу. Основаниями договорных обязательств служат регулируемые законом действия по заключению соглашения (ст. 8, 307, 307.1, 420, 432 ГК РФ), а также устраняющие состояние правовой неопределенности исполнительские действия сторон формально незаключенного договора (п. 3 ст. 432 ГК, п. 2 ст. 431.1 ГК). В качестве правового основания договор рождает обязательство - личную юридическую связь поименованных субъектов, содержанием которой являются их права и обязанности, взимообусловленные встречным исполнением [13, с. 53-55].

Действия по причинению вреда, вследствие которых возникают деликтные обязательства, закон не регулирует, а запрещает, в связи с чем в цивилистике их за редким исключением $[5$, с. 7,17$]$ считают мерой ответственности, утверждая, что «обязанность возместить вред выступает как мера ответственности, в основе которой лежит состав правонарушения, определенное сочетание условий ответственности, вина (за исключением случаев, указанных в п. 1 ст. 1070 ГК), действует презумпция вины причинителя вре- да» [2]. Вместе с тем подход к основанию деликтного обязательства как к правонарушению не основан нормативно, состав правонарушения определяется учеными «как научная, теоретическая абстракция, поскольку не имеет общего законодательного определения в нормах права» $[4$, с. $13 ; 11$, с. 11,13$]$. Скорее всего, именно по этой причине вопрос о понятии и составе гражданского правонарушения является остро дискуссионным [1, с. 14-20].

Не поддерживая квалификацию деликтных обязательств в качестве меры ответственности, отметим наличие самостоятельного гражданско-правового механизма возникновения обязательства вследствие причинения вреда: формальная определенность деликтного обязательства «устанавливается, если реализовано и признается самим причинителем вреда либо судом притязание потерпевшего на возмещение ущерба» [10, с. 11]. А это происходит далеко не всегда, поскольку «в жизни общества не каждое действие, наносящее вред другому лицу, может стать достаточным основанием для возмещения вреда» [14, с. 133]. Тем самым, акт причинения вреда, создавая состояние правовой неопределенности, служит основанием для притязания на защиту. Действия по защите любого нарушенного права регулируются законом. Поэтому 
обязательство по возмещению вреда, если его рассматривать как личную связь причинителя вреда и потерпевшего, устанавливается в качестве правового последствия правомерных действий по защите нарушенного права. Наличие опосредованной связи деликтного обязательства с актом причинения вреда не означает, что непосредственно этот акт его и порождает: любое обязательство - и договорное и внедоговорное - это следствие правомерных действий субъектов. Только в случае с договорным обязательством это волевые, двусторонние действия сторон договора по достижению соглашения, а при внедоговорном обязательстве - это инициативно-притязательные действия одного лица в ответ на нарушение его прав другим лицом. В связи с этим акт причинения вреда есть причина «оживления» правомочия защиты, осуществление которого происходит как притязание на возмещение вреда, и представляется важным определить нормативно-правовой механизм перехода притязания лица в состояние правообладания, связывающего другое лицо гражданско-правовой обязанностью.

В п. 1 ст. 1064 ГК РФ сказано: «Вред, причиненный личности или имуществу гражданина, а также вред, причиненный имуществу юридического лица, подлежит возмещению в полном объеме лицом, причинившим вред. Законом обязанность возмещения вреда может быть возложена на лицо, не являющееся причинителем вреда».

Буквальное прочтение нормы п. 1 ст. 1064 ГК приводит к выводу, что притязать на возмещение вреда можно, если: 1) есть вред и 2) персонифицировано лицо, с деянием которого вредоносный результат связан признаками вероятности и неизбежности, либо установлено лицо, на которого законом может быть возложена обязанность возмещения. Тем самым в норме п. 1 ст. 1064 ГК указано одно единственное основание, в связи с которым потерпевшее вред лицо может притязать на установление обязанности для причинившего вред лица. И это основание - причинение вреда (в форме деяния и в виде результата). Следовательно, если результатом действий одного лица (причинителя) стало умаление материального или нематериального блага (объекта прав) другого лица (потерпев- шего), у потерпевшего появляются основания для защиты нарушенного права посредством обоснования: 1) обязанности причинителя восстановить положение потерпевшего в прежнем состоянии либо 2) обязанности по выплате компенсации, достаточной для устранения последствий, вызванных деянием причинителя вреда.

Актом причинения вреда деликтное обязательство не порождается уже хотя бы потому, что причинитель вреда может остаться неизвестным, а также потому, что потерпевший может и не проявить свою волю на защиту в силу самых разных причин. Как известно, в гражданском праве, в отличии от публичного, именно правообладателю предоставлена возможность ставить вопрос о придании обстоятельствам произошедшего юридического характера. Акт причинения вреда (деяние) дает такую возможность, однако сам по себе обязательство из причинения вреда не порождает, для этого требуется сравнительно-правовая оценка (юридическая квалификация) произошедшего. Это происходит во время защиты, когда, реализуя свое притязание, «потерпевший должен доказать возникновение вреда и его размер, а также то, что ответчик является причинителем вреда или лицом, обязанным его возместить» [8]. Право на возмещение вреда, как любое другое имущественное право, не может быть безобъектным, поэтому для установления деликтного обязательства вид и объем вреда, а также способ и размер его возмещения подлежат определению и подсчету. И происходит это в судебном или внесудебном процессе по защите нарушенного права.

Заметим, п. 1 ст. 1064 ГК не содержит критериев оценки правомерности или противоправности деяния, которым причиняется вред. Также норма не предписывает определять субъективное отношение причинителя вреда ни к самому вредоносному действию, ни к наступившему в связи с ним результату. Сравним с содержанием нормы параграфа 823 «Обязанность возместить вред» ГГУ 1896 г.: «Кто противозаконно, умышленно или неосторожно лишит жизни человека, причинит ему телесное повреждение или расстройство здоровья, посягнет на его свободу, собственность или какое-либо другое право, тот обязан воз- 
местить ему причиненный этим вред» [3]. В данном случае норма прямо содержит требования определять противозаконность, умышленность или неосторожность вредоносного действия.

Следуя логике п. 1 ст. 1064 ГК, п. 2 этой статьи надо изложить так: «Лицо освобождается от возмещения вреда, если докажет, что вред причинен не в связи с его деянием, либо деяниями, дозволенными законом или договором». В качестве дозволенных действий закон определяет причинение вреда в пределах необходимой обороны (ст. 1066 ГК) и в состоянии крайней необходимости (ст. 1067 ГК), а также, например, если вред причинен по просьбе или с согласия потерпевшего, а действия причинителя вреда не нарушают нравственные принципы общества (п. 3 ст. 1064 ГК). Примером дозволенных договором действий можно назвать порчу плодородного слоя земли при строительстве автомобильных дорог общего пользования по госконтракту: несмотря на то, что порча земли - это заведомо противоправное, виновное действие, с неизбежностью производящее вред в полосе постоянного и временного отвода земель, оно совершается по заданию заказчика и от него нельзя защищаться, притязая на возмещение вреда подрядчиком [9].

Ныне действующее правило нормы п. 2 ст. 1064 ГК («Лицо, причинившее вред, освобождается от возмещения вреда, если докажет, что вред причинен не по его вине») логически с нормой п. 1 ст. 1064 ГК не связано, более того, оно указывает на оправдательные обстоятельства субъективного свойства, в то время как обязанность по возмещению вреда возникает в силу объективно существующей причинно-следственной связи между действием и его вредоносным результатом. И, исходя из принципа баланса частных интересов, нет смысла доказывать вину или ее отсутствие в условиях объективно существующей причинной связи между действиями причинителя вреда и наступившим вредом. В этих условиях для того, чтобы обосновать или опровергнуть притязание на возмещение вреда, достаточно доказать дозволенность или недозволенность вредоносного действия. Правильность сделанного вывода подтверждает позиция Конституционного суда РФ, который указал федеральному законодателю на необходимость внести в действующее правовое регулирование изменения, направленные на совершенствование правового механизма реализации потерпевшим права на возмещение имущественного вреда, причиненного в связи с угоном и последующей кражей принадлежащего ему автомобиля. В случае кражи неизвестным лицом ранее угнанного автомобиля имущественный вред потерпевшему возмещает лицо, совершившее угон [7]. Логика в том, что если угон автомобиля - действие недозволенное, а последующая его кража произошла в связи с угоном, значит угон является причиной утраты автомобиля. Если исключить кражу автомобиля, то при установлении лица, совершившего угон, собственник получает реальную возможность потребовать его возврата посредством виндикации, а в случае повреждения автомобиля еще и возмещения причиненного его собственности ущерба. Последующая кража автомобиля неустановленным лицом лишает его этих возможностей. И именно причинно-следственная связь действий угонщика с утратой автомобиля лежит в основании установления его обязанности по возмещению вреда. Расширим сферу применения правила о причинно-следственной связи и получим формулу: если недозволенные деяния поименованного лица стали причиной вреда, его же действия должны стать причиной устранения вредоносных последствий недозволенных деяний, то есть причиной «такого состояния, которое правопорядок хотел... сохранить путем установления запрета» [12, с. 244].

Таким образом, акт причинения вреда с юридической стороны - это нарушение субъективного права, обеспеченного абсолютной защитой. И он активизирует правомочие защиты в части возможности притязать на возмещение вреда. Притязание выражается в правомерном требовании, предъявляемом с целью восстановления прежнего (до нарушения) положения потерпевшего от вреда за счет его причинителя. Для обоснования притязания на защиту достаточно доказать, что деяние, которым причинен вред: 1) не дозволено (запрещено) законом либо совершено за пределами дозволенного и что оно 2) с неизбежностью вызывает тот вредоносный результат, об 
устранении которого просит потерпевший. Субъективная оценка деяния не имеет правоустанавливающего значения, точно так же, как и его противоправный или правомерный характер - закон запрещает причинять вред не только незаконными действиями, но также и правомерными (ст. 16.1 ГК). Исключить возникновение обязанности возмещать вред можно только доказав, что его причинение дозволено законом или договором. Логика в том, что если одному дозволено совершать вредоносные деяния, значит другим вменяется претерпевать их последствия, а если не дозволено, - значит и от самих деяний и от наступающих в связи с ними последствий можно защищаться, притязая на их устранение.

\section{СПИСОК ЛИТЕРАТУРЫ}

1. Агибалова, Е. Н. Состав гражданского правонарушения как основание деликтной ответственности / Е. Н. Агибалова // Налоги. - 2010. - № 7. C. 14-20.

2. Андреев, Ю. Н. Ответственность государства за причинение вреда: цивилистические аспекты / Ю. Н. Андреев. - СПб. : Юридический центр Пресс, 2013. - 374 с.

3. Германское гражданское уложение 1896 года: в 5 кн. - Кн. 2, разд. 7: Отдельные обязательства. Электрон. текстовые дан. - Режим доступа: https:// ru.wikisource.org/wiki/Германское гражданское уложение/Книга_2/Раздел_7. -Загл. с экрана.

4. Лиховидов, К. С. Актуальные проблемы теории юридической ответственности / К. С. Лиховидов // Юрист. - 2002. - № 3. - С. 13.

5. Матвеев, Г. К. Основания гражданско-правовой ответственности / Г. К. Матвеев. - М. : Юрид. лит., 1970.- С. 7, 17.

6. Матвеев, Г. К. Основания юридической ответственности / Г. К. Матвеев // Советское государство и право. - 1971. - № 10. - С. 30.

7. Постановление Конституционного суда РФ «По делу о проверке конституционности положений пунктов 1 и 2 статьи 1064 Гражданского кодекса Российской Федерации и пункта “а” части второй статьи 166 Уголовного кодекса Российской Федерации в связи с жалобой гражданина В.В. Кряжева» от 07 апр. 2015 г. № 7-П // Собрание законодательства РФ. - 2015. - № 16. - Ст. 2460.

8. Постановление Пленума Верховного суда РФ от 26 янв. 2010 г. № 1 п. 11; Определение Верховного суда РФ от 01 апр. 2014 г. № 5-КГ14-11, от 12 сент. 2014 г. № 22-КГ14-15. - Доступ из справ.-правовой системы «КонсультантПлюс».
9. Решение АС НО от 15 янв. 2016 г. по делу № А; №-19464/2014. - Электрон. текстовые дан. - Режим доступа: https://kad.arbitr.ru. - Загл. с экрана.

10. Рзаев, О. Ш. Притязание на возмещение ущерба в обязательствах из причинения вреда / О. Ш. Рзаев // Законы России: опыт, анализ, практика. -2017. - № 11.- С. 11.

11. Толстой, Ю. К. Обязательства, возникающие вследствие причинения вреда // Гражданское право : учебник. В 3 т. Т. 3. / под ред. А. П. Сергеева, Ю. К. Толстого. -4-е изд., перераб. и доп. - М. : ТК «Велби»; Проспект, 2005. - С. 11, 13.

12. Тон, А. Правовая норма и субъективное право. Исследования по общей теории права / А. Тон // Вестник гражданского права. - 2013. - № 1.

13. Чеговадзе, Л. А. Договор и договорное регулирование / Л. А. Чеговадзе, А. А. Демин. - Нижний Новгород : НОЦ «Цезиус», 2014. - 206 с.

14. Шапп, Я. Система германского гражданского права : учебник / Я. Шапп ; пер. с нем. С. В. Королева. - М. : Междунар. отношения, 2006. -360 с.

\section{REFERENCES}

1. Agibalova E.N. Sostav grazhdanskogo pravonarusheniya kak osnovanie deliktnoy otvetstvennosti [The Elements of a Civil Violation as a Basis of Tort Liability]. Nalogi, 2010, no. 7, pp. 14-20.

2. Andreev Yu.N. Otvetstvennost gosudarstva za prichinenie vreda: tsivilisticheskie aspekty [State Liability for Damage: Civil Law Aspects]. Saint Petersburg, Yuridicheskiy tsentr Press, 2013. 374 p.

3. Germanskoe grazhdanskoe ulozhenie 1896 goda: $v 5 \mathrm{kn}$. Kn. 2, razd. 7: Otdelnye obyazatelstva [The German Civil Code of 1896. In 5 Books. Book 2, Section 7: Certain Obligations]. URL: https://ru. wikisource.org/wiki/Germanskoe_grazhdanskoe_ ulozhenie/Kniga_2/Razdel_7.

4. Likhovidov K.S. Aktualnye problemy teorii yuridicheskoy otvetstvennosti [Urgent Problems of the Theory of Legal Liability]. Yurist, 2002, no. 3, p. 13.

5. Matveev G.K. Osnovaniya grazhdanskopravovoy otvetstvennosti [Grounds for Civil-Legal Responsibility]. Moscow, Yurid. lit. Publ., 1970,pp. 7, 17.

6. Matveev G.K. Osnovaniya yuridicheskoy otvetstvennosti [Grounds for Legal Responsibility]. Sovetskoe gosudarstvo i pravo, 1971, no. 10, p. 30.

7. Postanovlenie Konstitutsionnogo suda RF «Po delu o proverke konstitutsionnosti polozheniy punktov 1 i 2 statyi 1064 Grazhdanskogo kodeksa Rossiyskoy Federatsii i punkta "a" chasti vtoroy statyi 166 Ugolovnogo kodeksa Rossiyskoy Federatsii v svyazi s zhaloboy grazhdanina V.V. Kryazheva» ot 07 apr. 2015 g. N 7-P [Resolution of the Constitutional Court of the Russian Federation "On Verification of 
Constitutionality of Provisions of Paragraphs 1 and 2 of Article 1064 of the Civil Code of the Russian Federation and Paragraph "a" of Part Two of Article 166 of the Criminal Code of the Russian Federation Due to the Complaint by Citizen V.V. Kryazhev" of April 7, 2015 no. 7-P]. Sobranie zakonodatelstva RF [Collected Legislation of the Russian Federation], 2015, no. 16 , Art. 2460.

8. Postanovlenie Plenuma Verkhovnogo suda RF ot 26 yanv. 2010 g. N 1 p. 11; Opredelenie Verkhovnogo suda RF ot 01 apr. 2014 g. N 5-KG1411 , ot 12 sent. $2014 \mathrm{~g}$. N 22-KG14-15 [Resolution of the Plenum of the Supreme Court of the Russian Federation of January 26, 2010 no. 1, para. 11; Decision of the Supreme Court of the Russian Federation of April 1, 2014 no. 5-KG14-11, of September 12, 2014 no. 22-KG14-15]. Access from Reference Legal System "KonsultantPlyus".

9. Reshenie AS NO ot 15 yanv. 2016 g. po delu № A; №-19464/2014 [Decision of the Arbitration Court of the Nizhnyy Novgorod Region of January 15, 2016 on Case no. A; no. 19464/2014]. URL: https://kad. arbitr.ru.
10. Rzaev O.Sh. Prityazanie na vozmeshchenie ushcherba $\mathrm{v}$ obyazatelstvakh iz prichineniya vreda [Claim for Reimbursement of Damage in Tort Obligations]. Zakony Rossii: opyt, analiz, praktika, 2017, no. 11, p. 11.

11. Tolstoy Yu.K. Obyazatelstva, voznikayushchie vsledstvie prichineniya vreda [The Obligations Arising Due to Infliction of Harm]. Sergeev A.P., Tolstoy Yu.K., eds. Grazhdanskoe pravo: uchebnik. V 3 t. T. 3. [The Civil Law: Textbook. In 3 vols. Vol. 3]. Moscow, Velbi Publ.; Prospekt Publ., 2005, pp. 11, 13.

12. Tone A. Pravovaya norma i subyektivnoe pravo. Issledovaniya po obshchey teorii prava [Legal Regulation and Subjective Law. Research on the General Theory of Law]. Vestnik grazhdanskogo prava, 2013, no. 1.

13. Chegovadze L.A., Demin A.A. Dogovor $i$ dogovornoe regulirovanie [The Contract and Contractual Regulation]. Nizhniy Novgorod, Tsezius Publ., 2014. 206 p.

14. Chappe J. Sistema germanskogo grazhdanskogo prava [The System of German Civil Law]. Moscow, Mezhdunar. otnosheniya Publ., 2006. 360 p.

\section{Information about the Author}

Lyudmila A. Chegovadze, Doctor of Juridical Sciences, Professor, Department of Civil Law and Procedure, Russian Presidential Academy of National Economy and Public Administration, Prosp. Vernadskogo, 84, 119606 Moscow, Russian Federation; N.I. Lobachevsky State University of Nizhny Novgorod, Prosp. Gagarina, 23, 603950 Nizhny Novgorod, Russian Federation, chegov@mail.ru.

\section{Информация об авторе}

Людмила Алексеевна Чеговадзе, доктор юридических наук, профессор кафедры гражданского права и процесса, Российская академия народного хозяйства и государственной службы при Президенте РФ, просп. Вернадского, 84, 119606 г. Москва, Российская Федерация ; Нижегородский государственный университет им. Н.И. Лобачевского, просп. Гагарина, 23, 603950 г. Нижний Новгород, Российская Федерация, chegov@mail.ru. 